\title{
Ecological niches and affordances in second language acquisition, learning, and teaching
}

\author{
CHARLOTTE SUN JENSEN
}

The aim of this article is to combine recent cognitive language theories with the field of second language acquisition, learning and teaching. This will be achieved through a theoretically reasoned critique of representative approaches within the existing second language teaching methods and research from a cognitive ecological perspective with a special focus on the theory of niches and affordances. The starting point for the critique is that language schools rarely focus on the learning and acquisition potential that exists outside language schools. This might be the reason why many learners rarely use their target language outside the classroom. An analysis of language school materials shows that the teaching seeks continuity and similarity between classroom activities and homework, despite the fact that learners are not doing homework in class. A central criticism of the second language research that focuses on learners' everyday lives is that they either reduce opportunities for learning and acquisition, or overlook some important didactic aspects. This article makes a didactic proposal as to how the theory and teaching can be combined in order to create a dynamic, situated, and differentiated learning process. 